\title{
La problemática (necesaria y siempre insuficiente) fundamentación de los derechos humanos
}

\author{
The problematic (necessary and always insufficient) \\ basis of human rights
}

Demetrio Velasco

Universidad de Deusto

dvelasco@deusto.es

doi: http://dx.doi.org/10.18543/djhr.1874

Fecha de recepción: 03.02.2020

Fecha de aceptación: 06.07.2020

Cómo citar/Citation: Velasco, Demetrio. 2020. "La problemática (necesaria y siempre insuficiente) fundamentación de los derechos humanos». Deusto Journal of Human Rights, No. 6: 69-97. doi: http://dx.doi.org/10.18543/djhr.1874.

Sumario: Introducción. 1. La fundamentación filosófica de los Derechos Humanos. 1.1. La naturaleza problemática de los derechos humanos. 1.2. La construcción histórica de los derechos humanos. 1.3. Las diferentes generaciones de derechos humanos. 1.4. Universalidad y particularismo de los derechos humanos. 1.5. ¿Fundamentación de los derechos humanos? 1.6. Algunas propuestas significativas. 2. Repensar los derechos humanos desde el mundo de los «sin derechos». 2.1. Hacia un nuevo orden ontológico revolucionario, hoy. Referencias bibliográficas.

Resumen: Los Derechos Humanos han sido por su intrínseca historicidad radicalmente problemáticos. Desde su creación, fueron expresión de un nuevo imaginario social de carácter revolucionario que rompió con la cosmovisión de la sociedad premoderna. Pero la misma historia ha evidenciado su insuficiencia teórica e incluso su perversión práctica, a la hora de alcanzar sus objetivos. «Toda sociedad en la cual la garantía de los derechos no esté asegurada ni la separación de poderes establecida no tiene Constitución» (Declaración de los Derechos del Hombre y del Ciudadano de 1789, art. 16). Hoy, vivimos una situación de fascismo social y de desigualdad tan inhumanos que se han convertido en una amenaza letal para la supervivencia de gran parte de la humanidad y también del ecosistema global que la posibilita. Es hora de crear un «nuevo orden ontológico revolucionario» desde el que garantizar la "verdad práctica», la legitimidad política y la plausibilidad histórica del constitucionalismo del futuro. Debemos comenzar por eliminar el racismo institucional y el sadismo administrativo con los que rechazamos a los inmigrantes en las fronteras de nuestra civilizada Europa. 
Palabras clave: derechos humanos, fundamentación filosófica, universalidad vs. particularismos.

Abstract: Human rights have been, because of their intrinsic historicity, radically problematic. Since their creation, they have been the expression of a new social imaginary of a revolutionary nature that broke with the worldview of pre-modern society. But history itself has shown their theoretical insufficiency and even their practical perversion, when it comes to achieving their objectives. "Any society in which no provision is made for guaranteeing rights or for the separation of powers, has no Constitution» (Declaration of Rights of Man and of the Citizen of 1789, art. 16). Today, we live in a situation of social fascism and inequality so inhuman that they have become a lethal threat to the survival of a large part of humanity and also of the global ecosystem that makes it possible. It is time to create a "new revolutionary ontological order» from which to guarantee the "practical truth», political legitimacy and historical plausibility of the constitutionalism of the future. We must start by eliminating the institutional racism and administrative sadism with which we reject immigrants at the borders of our civilized Europe.

Keywords: human rights, philosophical basis, universality vs. particularism 


\section{Introducción}

En febrero de 2007 fui invitado para intervenir en las III Conversaciones de Filosofía, en la Universidad de las Palmas, dedicadas a la «Fundamentación filosófica de los derechos humanos». Titulé mi ponencia "La necesaria y siempre insuficiente fundamentación de los Derechos Humanos». Cuando he pensado en si aquella ponencia, todavía inédita, podría servir como referencia básica, y tras releer el texto, me ha parecido oportuno reproducirlo porque creo que sigue teniendo vigencia y actualidad lo que se dice sobre la problemática naturaleza de los derechos humanos, sobre su construcción histórica a lo largo de sus diferentes generaciones, sobre sus contradicciones entre su universalidad y particularismos.

El tiempo transcurrido desde la mencionada ponencia me ha ido mostrando que tanto el presente de los derechos humanos, como su inmediato futuro, están siendo seriamente amenazados por una deriva de nuestras sociedades y del mundo, en general, que puede ser calificada de "fascismo social», por utilizar la expresión de B. de Sousa (2009: 560-563). Hace unos años yo mismo escribí sobre esta cuestión (Velasco 2013a). No creo exagerado afirmar que hemos llegado a una situación en la que no se puede seguir manteniendo el discurso convencional sobre los derechos humanos ni la legitimación de las instituciones jurídico-políticas que nacieron para garantizar su progresiva implantación, lastradas por el particularismo etnocentrista. Como explicitaré en las páginas finales del presente artículo, es preciso dar el paso a la creación de un «nuevo orden ontológico revolucionario», diferente al que inspiró las revoluciones liberales que vieron nacer las Grandes Declaraciones de Derechos del Hombre y a reformular la fundamentación del constitucionalismo moderno.

\section{La fundamentación filosófica de los Derechos Humanos}

En pocos temas como en este de los derechos humanos y de su fundamentación se hace tan necesaria la doble tarea que tradicionalmente se ha atribuido al pensamiento filosófico de clarificar conceptos y de valorar críticamente las creencias. En pocos temas como en este las razones de la coherencia lógica, es decir, el imperativo de pensar conforme a criterios más racionales, se deben retroalimentar con los criterios de la coherencia práctica, es decir, teniendo en cuenta las consecuencias que se derivan de la aplicación de dichas razones. La cuestión es, pues, si la teoría de los derechos, formulada con la coherencia de las Grandes 
Declaraciones, puede y debe ir acompañada de una coherencia práctica, que postule no sólo la normatividad propia de la necesidad moral, sino también la traducción jurídico-política que permita la construcción de sociedades democráticas en las que todos podemos convivir como sujetos libres e iguales y, sobre todo, en las que nadie, por ser débil, pueda ser negado o excluido por quienes se sienten más fuertes.

Mi convicción, al abordar el tema es que la fundamentación filosófica de los derechos humanos, por tratarse de una filosofía eminentemente "práxica», debe ser, a la vez, una actividad crítica, práctica y transformadora, y que, para ello, debe tener un carácter pluridisciplinar. En mi opinión, ética, política y derecho son dimensiones constitutivas y complementarias de un mismo proceso de construcción social de la realidad. La necesaria diferenciación de estos subsistemas o ámbitos de la realidad no debe traducirse en una separación radical o en una confusión de los mismos, ya que, si así fuera, pondríamos en grave riesgo la significatividad y vigencia de lo que la cultura occidental contemporánea ha juzgado como una herencia incuestionable: la de los derechos humanos. Como concluye Pérez-Luño (1994, 532), «no se trata de la expresión de meros buenos deseos teóricos, la articulación de las relaciones entre Derecho, Moral y Política concierne a nuestra labor intelectual, pero también a nuestra entera vida cívica y al inquirir estas cuestiones no somos observadores externos, porque, en definitiva, de nobis fabula narratur».

Al abordar la fundamentación filosófica de los derechos humanos creo, pues, relevante tanto distinguir, como, por ejemplo, lo hace Ferrajoli (2013), entre las diversas disciplinas que abordan los derechos humanos: la ciencia jurídica positiva, la filosofía política, la teoría del derecho, la sociología y la historiografía jurídicas, e incluso la cartografía jurídica, como hacerse eco de la polémica que el mismo Ferrajoli ha abierto al pretender defender una teoría del derecho, de claro matiz kelseniano, que a la vez que se dota del mayor rigor científico postula una clara dimensión normativa. Se trata, en definitiva, de una forma original de superar la dicotomía entre iusnaturalismo y positivismo. No voy a entrar a comentar, ahora, las cuestiones más importantes, que se pueden ver en el texto (Cabo y Pisarello 2005). Me limito a subrayar que me parecen clarificadoras sus aportaciones a la fundamentación axiológica de los derechos humanos y, especialmente, la dedicada a «los derechos humanos como leyes del más débil» ${ }^{1}$.

1 L. Ferrajoli (2013: 314-328) señala los «cuatro criterios axiológicos, todos ellos referidos al valor de la persona humana asumida como fin y nunca como medio, según la clásica máxima de la moral kantiana. Estos criterios, tal como expondré, sirven, 
Por mi parte, me limitaré a hacer algunas observaciones elementales a propósito de la creación de los derechos humanos, subrayando su historicidad y permanente transformación, para argumentar que la dimensión formal de su categorización es indisoluble de su contenido material. Argumentaré mi convicción de que es imposible afirmar los derechos humanos desde posiciones premodernas y antidemocráticas. Trataré de mostrar cómo su fundamentación es una actividad «práxica», de la que solamente podrán dar razón suficiente «las leyes del débil» o la razón de las víctimas. La obra de Dussel (2001) me

por un lado, para determinar las opciones ético-políticas a favor de los valores de la persona — vida, dignidad, libertad, supervivencia- que son establecidos positivamente como fundamentales bajo la forma de expectativas universales; $y$, por otro, son todos sugeridos por la experiencia histórica del constitucionalismo democrático, tanto estatal como internacional, que ha resultado, de hecho, orientada axiológicamente por ellos. El primero de estos criterios es el del nexo entre derechos fundamentales e igualdad... El segundo criterio, en conexión con el primero, es el del nexo entre derechos fundamentales y democracia... El tercer criterio es el del nexo entre derechos fundamentales y paz establecido en la Declaración universal de 1948... El cuarto criterio es el papel de los derechos fundamentales como leyes del más débil... en alternativa a la ley del más fuerte que imperaría en su ausencia... Dicho nexo consiste, creo, en la relación de racionalidad instrumental que liga medios afines, o sea, en la adecuación, relativamente verificable en el plano empírico, de una determinada conducta, técnica o artificio institucional respecto a los objetivos prefijados... Quiero decir que la forma universal de los derechos fundamentales identificada por mi definición teórica no es sino el medio o la técnica normativa racionalmente idónea, cuanto más extensas son las clases de sujetos a los que se refiere, para conseguir los fines o valores, a su vez no justificados sino postulados, que su concreta estipulación positiva persigue. Se trata, por tanto, de la forma lógica que deben adoptar las expectativas expresadas por tales derechos si queremos que, cualquiera que sea su contenido, queden tuteladas y satisfechas. A la pregunta sobre cuál es el fundamento axiológico de los derechos fundamentales diremos, por tanto, que no reside en ellos mismos, es decir, según su definición, en su forma universal, sino en los fines para cuya obtención dicha forma es un medio necesario, aunque, obviamente, por sí solo insuficiente. Estos fines son, justamente, aquellos a los que se refieren mis cuatro criterios: la igualdad en las expectativas asumidas axiológicamente como fundamentales, como los derechos a la vida, a algunas libertades y a la autodeterminación civil y política; la democracia, resultante, en sus distintas dimensiones, de la realización de la igualdad en otros tantos tipos de derechos; la paz, o sea, la pacífica convivencia proveniente, según el paradigma kantiano, de la convivencia entre los derechos fundamentales de cada uno y los de todos; la tutela del débil frente al abuso del más fuerte, que aquéllos pueden impedir $\mathrm{o}$, en todo caso, limitar. Es en estos fines donde residen los valores, y es en la voluntad de realizarlos donde intervienen las opciones ético-políticas, ajenas, en cambio, a las definiciones teóricas y las tesis dogmáticas. Por lo que, por lo que se verá, lo que el relativismo y el diferencialismo cultural deberían cuestionar no es el universalismo de los derechos, sino los valores concretos - la vida, la igualdad dignidad de las personas, la paz y la democracia- que, gracias a su forma universal, queremos realizar y que no resultan realizables sin tal forma». 
servirá de referencia. Apuntaré la relevancia de obras como la suya o la de B. de Sousa (2009).

He querido titular este texto como «la problemática (necesaria y siempre insuficiente) fundamentación de los derechos humanos», porque parto de la convicción de que en éste tema, como en algunos otros de carácter antropopolítico (como la construcción sociopolítica de la sociedad humana), estamos condenados a buscar una salida razonable a un problema siempre pendiente de encontrar la solución menos inadecuada: cómo vivir juntos, en libertad y siendo iguales porque diferentes.

Los derechos humanos han sido por su intrínseca historicidad radicalmente problemáticos. Desde su creación, como expresión del nuevo imaginario social de las sociedades modernas, los derechos humanos han sido fuente de conflicto social e ideal inspirador de procesos revolucionarios, cuya legitimidad ha sido puesta en duda por innumerables sujetos sociales y con diferentes discursos filosóficos. La "construcción negativa de los derechos humanos», expresión que he utilizado en algún escrito para referirme a las críticas teóricas que cuestionan los derechos humanos, desde su primera formulación programática en el contexto de las Revoluciones liberales hasta nuestros días (pensamiento reaccionario, pensamiento conservador, liberalismo doctrinario, marxismo, particularismos etnoraciales) es la evidencia histórica de lo dicho (Velasco 1999: 205-308).

Taylor (2006) se refiere al ideal moral que refleja el iusnaturalismo racionalista del s. XVII (Grocio y Locke) como el referente secular que va a posibilitar la construcción de un imaginario social que, a pesar de los muchos e importantes cambios, seguirá vigente hasta nuestros días²:

Así, pues, la idea moderna de orden moral no sólo se extiende de un contexto a otro y pasa del terreno teórico al imaginario social, sino que viaja también a lo largo de un tercer eje, y genera discursos

2 Sobre el alcance sociológico del nuevo imaginario, Ferrajoli (2013), dice que no sólo no era mayoritario, sino que no tenía por qué serlo (ni Beccaria con su obra, ni la Declaración Universal de 1789 habrían logrado un consenso mayoritario). No hay que confundir, como lo hace el relativismo cultural, el «universalismo» de los derechos fundamentales que se refiere a los sujetos a los que son atribuidos (jtodos!) con la universalidad del consenso en virtud del cual se sostienen. La mayoría no es el criterio último de legitimidad democrática, cuando ésta es constitucional. Los derechos humanos son precisamente derechos contra la mayoría. Por eso, tutelar un derecho como fundamental es sustraerlo a la política, esto es, a los poderes de las mayorías contingentes y al mercado. Ninguna mayoría, ni siquiera la unanimidad pueden decidir su abolición o reducción. 
que se van desplazando de lo inmanente a lo prescriptivo. En el proceso entra en combinación con un amplio abanico de conceptos éticos, de modo que las amalgamas resultantes tienen en común una dependencia fundamental respecto a una concepción del orden moral y político heredero de la teoría de la ley natural. [...] La idea de un orden moral no se limita al conocimiento y aceptación de una serie de normas, sino que añade el reconocimiento de una serie de rasgos en el mundo, en la acción divina o en la vida humana que hacen que ciertas normas sean a un tiempo buenas y (en la medida en que se indique) realizables. En otras palabras, la imagen del orden moral no sólo supone una definición de lo que es justo, sino también el contexto que da sentido a luchar por ello y esperar su realización (aunque solo sea parcial). Taylor $(2006,31)$.

Al hablar, pues, de los derechos humanos, me estoy refiriendo no a un fenómeno intemporal y abstracto, sino a «una creación de la historia moderna que refleja un momento crucial en la toma de conciencia sobre nuestra propia condición humana, al ser un fruto nacido tanto de trágicas experiencias de inhumanidad como de heroicas experiencias de liberación» ${ }^{3}$. Como toda creación humana, son la expresión de un contexto histórico e ideológico que necesita ser adecuadamente comprendido, tanto en sus orígenes como en sus diferentes etapas o "generaciones».

Tratar de fundamentar filosóficamente los derechos humanos exige saber previamente de qué estamos hablando en realidad. Creo imprescindible explicitar, aunque sea de forma muy esquemática, lo que entiendo por su naturaleza histórica y problemática y por las aporías congénitas de su vocación universal. La fundamentación filosófica de los derechos humanos tendrá el reto de convertir esta realidad, que alguien ha llamado despectivamente el «esperanto moral de las sociedades modernas» y que funciona como una especie de ideología de convergencia, en algo más que una convención útil. ¿Podremos mostrar que los derechos humanos más que expresiones vagamente interiorizadas de reglas externas pueden ser, todavía hoy, expresión de un imaginario social cuyo potencial crítico es capaz de

3 E. Dussel (2001) dirá que este imaginario moderno nacerá lastrado, como la filosofía que lo explica y legitima, por un racionalismo y por un formalismo ajenos a la verdadera lógica de la liberación. La modernidad olvidará, hasta nuestros días, que las «fuentes del yo» no hay que buscarlas sólo, ni siquiera en primer lugar, en el cogito artesiano, cuanto en el ego conquiro. Pensar filosóficamente los derechos humanos obliga, dirá Dussel, a una reconstrucción de cierta fundamentación de los mismos que se ha hecho sin tener en cuenta a los verdaderos sujetos humanos reconocidos universalmente como carentes de derechos y libertades. 
ir transformando las relaciones humanas en conformidad con el ideal moral que lo nutre? Escribo estas páginas desde la convicción de que para comprender adecuadamente la realidad de los derechos humanos hay que distanciarse tanto del pesimismo antropológico, que desiste de orientarse por otro criterio distinto al de la realpolitik o que, víctima de una actitud antiilustrada y antimoderna, desconoce la grandeza de esta construcción moderna de la realidad que llamamos derechos humanos, como de un optimismo voluntarista e ingenuo, que ignora la problemática complejidad que ha acompañado a los derechos humanos desde sus orígenes, tanto en su misma formulación teórica, como en su aplicabilidad. Creo que la fundamentación de los derechos humanos ha sido prisionera de una dialéctica entre el jusnaturalismo y el positivismo que no ha sabido dar razón suficiente de su realidad efectiva.

\subsection{La naturaleza problemática de los derechos humanos}

Los derechos humanos se tienen por el mero hecho de ser un "ser humano», por lo que los seguimos definiendo como universales, inalienables y absolutos, en el sentido de que deben predicarse de todos y cada uno de los seres humanos, de que son irrenunciables y de que no pueden instrumentalizarse para otro tipo de requerimientos, por importantes que estos sean. Cuando hablamos de derechos humanos no nos referimos, pues, ya a aquellos listados de derechos, recogidos en los bill of rights ingleses, por ejemplo, en los que se reconocían derechos a unos seres humanos, por tener una condición social concreta o pertenecer a un país concreto, pero sin que estos tuvieran vocación alguna de universalización. Serán los colonos americanos quienes, al romper con su condición de ingleses, reclamarán los atributos asociados a una nueva noción de individualidad humana, cuyo carácter ontológico será reflejo de la nueva autocomprensión, y de la que las Declaraciones de derechos humanos pretenderán dar razón. "Que todos los hombres son por naturaleza libres e independientes y tienen ciertos derechos innatos» (Declaración de Derechos del Buen Pueblo de Virginia. 12/VI/1776). "Sostenemos por evidentes, por sí mismas, estas verdades; que todos los hombres son creados iguales. Que son dotados por su Creador de ciertos derechos inalienables» (Declaración de Independencia de Estados Unidos. 4/VII/1776). "La meta de toda asociación política es la conservación de los derechos naturales e imprescriptibles del hombre» (Declaración de los Derechos del Hombre y del Ciudadano. Art. 2 (26/NIII/1789). 
Sabemos que la autocomprensión de la condición humana que reflejan las grandes declaraciones de los derechos humanos ha sido fruto de unas experiencias históricas traumáticas, como fueron las revoluciones liberales, en las que hubo que romper con toda una tradición histórica y poder así fundar un «nuevo orden ontológico revolucionario». La forma en que las grandes Declaraciones de los Derechos del Hombre reflejaron este nuevo orden revolucionario fue la del «racionalismo jusnaturalista». Es verdad que ha habido y sigue habiendo autores que sitúan el nacimiento de los derechos humanos en el tomismo medieval o en el jusnaturalismo premoderno del humanismo cristiano. Sin embargo, los derechos humanos, como expresión de una nueva concepción de la individualidad humana, sólo han podido formularse, por vez primera, por un jusnaturalismo racionalista como el moderno, que sitúa al individuo humano como principio y como fin de la realidad sociopolítica, como un «sujeto político» que no debe "estar sujeto» de forma arbitraria. Este jusnaturalismo racionalista supone, como hemos dicho, una solución de continuidad respecto a toda la tradición de pensamiento anterior; sólo han podido nacer en sociedades seculares y pluralistas, que son las que se han visto inmersas en un proceso de relaciones complejas con la religión y han acabado por asumir que esta última no debe determinar otros ámbitos de lo real, como, por ejemplo, el jurídico político, y que han aprendido que el único camino para lograr una convivencia humana razonable pasa por el reconocimiento de los derechos y libertades de sus miembros ${ }^{4}$. Sólo una ruptura epistemológica y ontológica con la cosmovisión de las sociedades premodernas ha podido dar a luz un referente normativo como el de los derechos humanos, con el carácter racionalista e individualista del jusnaturalismo moderno. El mismo Taylor describe lo que supone, de ruptura en un orden "óntico», el imaginario moderno respecto al premoderno. En primer lugar, con la idea de una ley que ha gobernado el pueblo desde tiempos inmemoriales y, en cierto sentido, lo define como tal; en segundo lugar, con la idea de la correspondencia entre la jerarquía social y la del cosmos (complementariedad jerárquica).

Pero, también, es sabido cómo, desde su formulación inicial, esta nueva autocomprensión de lo humano tuvo que hacer frente a muchas e importantes resistencias. Algunas nacían de la defensa

${ }^{4}$ Este proceso de secularización es complejo, como, cada vez con más claridad, está mostrando la sociología de la religión. La secularización es un proceso complejo, y en el primer momento este ideal moderno seguía reflejando un orden divino, inmanente a la naturaleza de las cosas. 
a ultranza de un orden estamental y prerrevolucionario, hecho de privilegios y particularismos excluyentes, y, por tanto, radicalmente incompatible con la nueva situación revolucionaria; pero otras, no tan reaccionarias, rechazaban el nuevo orden porque lo creían hijo de la «lujuria ontológica», esa patología que, antes que para Nietzsche, será ya para muchos la enfermedad metafísica por excelencia del occidente moderno. Denuncias como la de Burke, que advertían de que «lo metafísicamente verdadero suele ser ética y políticamente falso», y que él dirigía a los revolucionarios franceses y a su concepción de los derechos humanos, arrojarán en adelante sobre el jusnaturalismo racionalista moderno la sombra de ser una formulación discutible para la adecuada comprensión de los derechos humanos y, sobre todo, para hacer factible su aplicabilidad.

De hecho, no deja de ser cierto que el jusnaturalismo racionalista ha estado hipotecado por una concepción de naturaleza humana carente de suficiente historicidad y cargada de excesivo dogmatismo. Las sucesivas reediciones históricas del jusnaturalismo, tras las correspondientes críticas de carácter empirista o positivista, han estado todas ellas lastradas, en mayor o menor medida, por estas mismas lacras. Su formulación abstracta de la universalidad de lo humano, sin tener en cuenta las mediaciones institucionales que han sido siempre constitutivas de toda relación humana, se ha realizado a espaldas de la compleja dinámica histórica.

Pero, en cualquier caso, ninguna de las deficiencias de las que el jusnaturalismo racionalista moderno pueda presentar justifica el que se niegue su privilegiado papel de ser el inaugurador de la nueva autocomprensión revolucionaria. No parece que ya sea plausible sostener que se pueden afirmar los derechos humanos desde posiciones premodernas, como la tomista, que desde un objetivismo providencialista rechaza los derechos subjetivos del individuo, por considerar que el subjetivismo moderno nace viciado por un nominalismo y un voluntarismo incompatibles con el orden cristiano. Mucho menos parece razonable pretender que la defensa de los derechos humanos es compatible con la defensa de las estructuras desigualitarias del Antiguo Régimen, o con formas de legitimación religiosa o tradicional del poder (Velasco 2004 y 2006). Ninguna sociedad que desconozca los derechos inalienables de la libertad e igualdad de sus miembros podrá hacer una recepción adecuada de los derechos humanos, ni podrá ser considerada jurídica y políticamente como legítima. "Toda sociedad en la cual la garantía de los derechos no esté asegurada ni la separación de poderes establecida no tiene Constitución» (DDHC. Art 16. 1789). 


\subsection{La construcción histórica de los derechos humanos}

Aunque durante siglos la fundamentación de los derechos y de las libertades se haya basado en un jusnaturalismo racionalista de carácter "deontológico» creador de un orden ideal normativo para la conducta humana, sin embargo, cada vez ha ido pareciendo más obvio que los derechos humanos son una construcción social de la realidad vinculada a un tiempo y a unas experiencias concretas. Este contexto ha sido subrayado gracias a una nueva mirada, a la vez histórica y sociológica, a los procesos de construcción social de la realidad. Algunos analistas lúcidos de los procesos sociales, como A. Tocqueville, nos han enseñado que, si bien el irresistible proceso de igualación de condiciones sociales que daría lugar a las revoluciones liberales, primero, y a las sociedades democráticas, más tarde, fue fruto de un largo periodo de incubación histórica, fue imprescindible que se diera un contexto histórico y social concreto en el que nació un nuevo imaginario social dominante, un nuevo sensorium commune u opinión pública, como el autor los llama, que tuvieron virtualidad suficiente para transformar la realidad a su imagen y semejanza. En efecto, entre el derecho y el hecho se encuentra algo inasible, «imaginario», pero irresistible, que Tocqueville llama opinión pública, y que pone a los hombres aparentemente más desiguales en una situación de igualdad y semejanza. La igualdad es el sensorium commune de la vida social democrática. «El principal efecto de la democracia es convertir al amo y al servidor en extraños, poniéndoles uno al lado del otro, en vez de uno sobre el otro... En democracia los hombres no son ni iguales de hecho, ni solamente de derecho» (Velasco 2005). Creo que, desde posiciones como esta, se abre la posibilidad de trascender la polémica miope entre jusnaturalismo y positivismo, en que se ha encerrado con frecuencia la discusión sobre la realidad de los derechos humanos.

Hoy sabemos que la jerarquización de lo que entendemos por atributos de lo humano, los derechos humanos, no es ya el simple reflejo de un orden natural objetivo y trascendente al quehacer humano, ni siquiera la expresión de una racionalidad como la jusnaturalista moderna, que crea un código deontológico con carácter universal y abstracto, sino que es fruto de la historicidad de la conciencia y de la praxis críticas de los excluidos, de los "sin-derechos», que llegado un momento han comenzado a gritar "no hay derecho». $Y$, cuando se grita "no hay derecho», es porque se ha tomado conciencia de que la situación en que se vive no es humanamente soportable y se exige otra situación mejor, que se ajuste de verdad a 
derecho. El profesor E. Dussel lo expone en un texto que me parece muy clarificador al respecto:

La dialéctica no se establece entonces entre «derecho natural a priori versus derecho positivo a posteriori», siendo el derecho natural la instancia crítica a priori del derecho positivo, reformable, cambiable, sino entre "derecho vigente a priori versus nuevo derecho a posteriori», siendo el nuevo derecho la instancia crítica (es decir: histórica) y el derecho vigente el momento positivo, reformable, cambiable. En este caso el «estado de derecho» es una condición histórica y el medio (Umwelt) evolutivo en la historia, que se manifiesta como la tradición creciente del mundo del derecho de una comunidad política que cuenta con la macro-institucionalidad del Estado. Los «sinderecho-todavía» cuando luchan por el reconocimiento de un nuevo derecho son el momento creador histórico, innovador, del cuerpo del derecho humano. No caemos así en el dogmatismo del derecho natural (solución fundacionalista metafísica ya inaceptable), pero tampoco en el relativismo (todo derecho vale por haberse impuesto por la fuerza en una época), o el mero contingencialismo (no hay principios universales), sino la conciliación de un universalismo no fundacionalista que muestra que los «nuevos» derechos son los exigidos universalmente (sea en una cultura, sea para toda la humanidad, según el grado de conciencia histórica correspondiente) a la comunidad política en el estado de su evolución y crecimiento histórico. No era factible (por las condiciones históricas concretas) el movimiento feminista en la Edad Media (aunque hubo heroicas anticipaciones), como tampoco era posible el ecologismo antes de la revolución industrial, cuando el Planeta aparecía todavía como una fuente inacabada de recursos y los efectos negativos sobre la reproducción de la vida eran casi no medibles (Dussel 2001, 152).

Esta nueva forma de obviar la dialéctica entre jusnaturalismo y positivismo permite plantear la fundamentación de los derechos humanos desde una perspectiva menos aporética y más abierta a la comprensión de la historia humana, en general, y de la realidad sociopolítica, en particular. La introducción de la clave hermenéutica de una conciencia práxica radicalmente crítica y transformadora, como es la de las víctimas, permite asimismo trascender, en gran medida, la disputa entre quienes creen que los derechos humanos no son estrictamente derechos, sino sólo valores, que necesitan positivizarse para alcanzar la categoría de derechos. Como dice Dussel $(2001,153)$ : 
La incorporación de «nuevos» derechos al «sistema de derecho», o la explosión de derecho «vigente», que ahora se transforma en "antiguo» por un "nuevo sistema de derecho» es fruto, no tanto de la explicación de un derecho natural todavía no descubierto, sino por la institucionalización de un «nuevo» derecho descubierto por las víctimas «sin derecho» fruto de la madurez histórica propia al desarrollo de la realidad humana (y de la conciencia política), del proceso civilizatorio de la comunidad política particular o de la humanidad en general. Dicho descubrimiento no es fruto ni de un estudio teórico ni de un voluntarismo de ciertos movimientos mesiánicos. Es fruto de la conciencia crítico-política de los grupos que sufren en su dolor los efectos negativos del estado-de-no-derecho de una dimensión humana que la madurez histórica ha desarrollado pero que el derecho no ha incluido todavía como exigencias que requieren institucionalidad pública.

Ética, política y derecho aparecen así como dimensiones constitutivas de un mismo proceso. Más adelante, abundaré en esta cuestión.

\subsection{Las diferentes generaciones de derechos humanos}

Una expresión patente tanto de esta historicidad de los derechos humanos como de su carácter problemático y conflictivo es su convencional clasificación por "generaciones»: la de los derechos civiles y políticos, la de los derechos socioeconómicos, la de los derechos culturales o la de los derechos medioambientales, la de los derechos a la «diferencia»... El conflictivo tránsito de los derechos civiles y políticos a los derechos socioeconómicos es una prueba evidente de que sólo fue posible exigir estos últimos cuando la sociedad fue madurando un «imaginario» para el que era irracional e injusto que solamente pudieran ser ciudadanos activos, con capacidad de decidir sobre el destino de todos, una minoría de privilegiados y propietarios. Fue imprescindible poner en cuestión tanto la injusta e irracional división de la sociedad entre ricos y pobres, como, sobre todo, la pertinencia del liberalismo doctrinario, doctrina hasta entonces hegemónica que legitimaba dicha división. Ya no bastaba con decir que quienes carecen de ciertos medios de vida o de ciertas capacidades probadas en el ejercicio de algunas profesiones liberales quedaban incapacitados para ejercer los derechos y libertades políticas, porque carecían del ocio necesario para el ejercicio de las mismas, sino que, dando la vuelta al argumento, se sostenía que quienes estaban incapacitados 
para ser sujetos activos de derechos, tenían derecho a gozar de las condiciones materiales necesarias para así poder ejercer en condiciones de libertad e igualdad dichos derechos. Los derechos subjetivos tienen una dimensión social que no debe ya ser silenciada como lo hacía el individualismo propietarista y excluyente. Desde que el imaginario social hegemónico deslegitimó el paradigma propietarista y excluyente burgués y legitimó el paradigma distributivo socialista, los derechos socioeconómicos se convirtieron en derechos humanos exigibles en nombre de la dignidad humana.

Obviamente, esto no significó que los derechos socieconómicos se afirmaran realmente en la práctica. La desigualdad injusta e irracional ha seguido siendo la herida más profunda del mundo, hasta nuestros días, y, desgraciadamente, nada parece indicar que no vaya a seguir siéndolo. Nada garantiza que, aunque hoy podamos hablar diacrónicamente de tres o cuatro generaciones de derechos humanos, la vigencia de las primeras se asegure cuando se reivindica la aplicación de las últimas. Lo que hemos dicho a propósito de historicidad y conflictividad de estas dos primeras generaciones, vale para todas las demás, ya que están profundamente interrelacionadas entre sí y son, por tanto, interdependientes, como ha quedado plasmado en las grandes Conferencias sobre Derechos humanos que se siguen celebrando sin solución de continuidad.

En nuestros días, esta dimensión histórico-social y conflictiva de los derechos humanos se está escenificando en la forma en que el multiculturalismo está poniendo en tela de juicio la vigencia y plausibilidad del "paradigma de la distribución» (el que busca garantizar la igualdad para poder afirmar la libertad) en un mundo tan pluralista y complejo como el nuestro. La apelación al «paradigma de la diferencia» (el que busca afirmar la diferencia de ciertos grupos humanos para poder garantizar su identidad), que muchas de las políticas identitarias llevan a cabo, está, en mi opinión, poniendo en serio riesgo la vigencia de derechos humanos de las primeras generaciones.

El que los seres humanos seamos, a la vez, individualidad y socialidad, el que no nos podamos poner de acuerdo definitivamente sobre lo que es mejor y preferible para todos y cada uno, el que no podamos garantizar adecuadamente la complementariedad entre libertad e igualdad, son razones más que suficientes para hablar de la constitutiva conflictividad de los derechos humanos y para justificar una búsqueda permanente de la solución menos inadecuada. Por eso, contradicciones como las que se dan entre dos derechos de igual contenido, pero de distintos titulares; entre derechos de diverso 
contenido y propios de distintos sujetos, o entre los derechos de sujetos individuales y los denominados derechos de sujetos colectivos, serán expresión de la naturaleza histórica y conflictiva de los derechos humanos.

\subsection{Universalidad y particularismo de los derechos humanos}

Una de las pretensiones originarias de los derechos humanos ha sido la de su universalidad, es decir, que se declaraban como atributos de todos y cada uno de los seres humanos, más allá de su condición particular. Sin embargo, pocas características de la naturaleza de los derechos humanos han sido tan cuestionadas y denunciadas como ésta. Hoy, en un mundo tan fragmentado como el nuestro, lo está siendo de forma especial. La acusación ya convencional en nombre de sus críticos más clásicos, como el pensamiento reaccionario, el marxismo o los particularismos etnorraciales, de que la pretendida universalidad de los derechos humanos ha sido siempre fuente y motivo de despotismo, ya que éstos sólo han podido ser ejercidos en nombre de una concepción equivocada de la naturaleza humana ${ }^{5}$, a la postre, solamente, en usufructo de una minoría de la población (burgueses, hombres, ciudadanos, occidentales), ha sido una constante hasta nuestros días. Tanto su formulación abstracta y formalista de la mano del jusnaturalismo racionalista, como su positivación jurídica de la mano del Estado nación, han pesado de forma decisiva a la hora de evaluar el significado y alcance de la universalidad de los derechos humanos. El hecho innegable de que su virtualidad, que ha permitido romper progresivamente muchos de los círculos del particularismo desigualitario y excluyente (religiosos, socioeconómicos, etnoculturales, de género, etc.), no haya conseguido romper algunas de las barreras más deshumanizadoras de nuestro mundo, que siguen teniendo que ver con la distribución de los recursos y con las relaciones de dominación y de explotación, sigue planeando como una corrosiva sospecha sobre la legitimidad de esta pretensión de universalidad.

¿Lo que acabamos de decir supone la negación de la universalidad de los derechos humanos? ¿Fue sólo una pretensión del jusnaturalismo racionalista carente hoy de vigencia? Creo que la

5 El concepto jusnaturalista de naturaleza humana no sólo ha sido abstracta y dogmática (con la pretensión de aplicarse «more geométrico» a todas las expresiones de la vida), sino también etnocentrista y excluyente (censitarismo). 
respuesta a esta cuestión exige, como lo hemos hecho hasta ahora, contextualizar lo que hoy puede significar el calificar de universales a los derechos humanos. En primer lugar, la universalidad no tiene por qué ser un logro adquirido en la práctica para poderse afirmar razonablemente como una pretensión legítima. Ya decíamos al comienzo que no hay que confundir la universalidad predicable de todos los seres humanos sujetos de derechos en nombre de su igual dignidad con la universalidad empírica que es siempre fruto de un acuerdo contingente. Nadie en sus cabales puede pretender que se cumpla el sueño de un paraíso terrestre, como el que sería el que todos los hombres, en todos los lugares y tiempo, logren aquello que idealmente decimos que es exigible por cada hombre. Basta con que sea un logro del imaginario social hegemónico de nuestro mundo y que se corresponda con un grado de conciencia adquirida sobre lo que significa la dignidad del ser humano y de los derechos que de esta se derivan. Basta con que dicho imaginario considere como irracionales e injustas las relaciones de dominación y exclusión entre individuos y grupos humanos, porque niegan la universalidad de la dignidad humana. Obviamente, basta siempre que no sea un recurso más de la razón cínica que se carga de razones para defenderse de la razón.

Pensar la universalidad exige tener en cuenta la forma particularista en que hemos construido nuestro mundo para saber responsabilizarnos de él y hacer nacer en nosotros la memoria passionis. Esto nos impide desconocer lo que de imperialismo ha habido en muchas de nuestras empresas llamadas "universales», incluso las etiquetadas de humanizadoras y evangelizadoras. Pensar la universalidad exige asumir que toda solidaridad humana es excluyente, porque no hay creación humana que no sea etnocentrista y reduccionista, y que una más amplia y efectiva realización de los derechos humanos debe perseguir aquellos objetivos que son factibles y plausibles en cada contexto histórico, aunque no se identifiquen con su realización perfecta. Pensar la universalidad de los derechos humanos supone asumir que su naturaleza utópica forma una parte irrenunciable de la tópica jurídica y política, porque gracias a ella podemos ir superando aquellas formas de organizar las relaciones humanas que nos parecen ilegítimas a la luz del imaginario social de los derechos humanos. La universalidad de los derechos es la que nos obliga a ponernos de acuerdo sobre lo que en cada momento histórico es más razonable. Más allá de los universalismos imperialistas o de los particularismos fundamentalistas, que acaban siendo las dos caras de una misma moneda, la universalidad de los 
derechos humanos debe ser la expresión de un consenso siempre necesitado de reformulación, ya que ni se conforma con ser una especie de esperanto moral ni debe correr el riesgo de crear una nueva babel destructiva de lo humano. Con esta universalidad «metodológica» se expresa la Conferencia de Viena, cuando afirma en el párrafo 5 de su Declaración:

Todos los Derechos Humanos son universales, indivisibles e interdependientes y están relacionados entre sí. La comunidad internacional debe tratar los Derechos Humanos en forma global y de manera justa y equitativa, en pie de igualdad y dándoles a todos el mismo peso. Debe tenerse en cuenta la importancia de las particularidades nacionales y regionales, así como los diversos patrimonios históricos, culturales y religiosos, pero los Estados tienen el deber, sean cuales fueran sus sistemas políticos, económicos y culturales, de promover y proteger todos los Derechos Humanos y las libertades fundamentales.

Aunque los argumentos aducidos en el tema de la universalidad son extrapolables a la cuestión de la fundamentación, conviene abordar más explícitamente esta cuestión.

\section{5. ¿Fundamentación de los derechos humanos?}

Si, como hemos visto, la problemática realidad de los derechos humanos hace muy difícil un consenso sobre su conceptualización, su universalidad y, sobre todo, sobre su realización, también dificulta seriamente un acuerdo sobre su fundamentación, hasta el punto de que es una de las cuestiones que más enfrentan a los teóricos. Hay autores que niegan de entrada toda posibilidad de fundamentación racional de los derechos humanos, ya que, como Maclntyre, afirman que no existen tales derechos y creer en ellos es como creer en brujas y unicornios. Hay otros, que, declarándose positivistas, niegan toda fundamentación jusnaturalista de los derechos humanos. Y, además, relativizan la cuestión de la fundamentación de los derechos humanos, porque, para ellos, lo importante es su reconocimiento y realización. Más importante que justificarlos es protegerlos. Ya no importa tanto encontrar el fundamento absoluto a los derechos humanos, sino los varios fundamentos posibles en función del contexto y de las condiciones sociales respectivas.

Si bien, hoy, no es posible sostener un discurso basado en una racionalidad última indiscutible, sigue siendo razonable y plausible 
postular una base racional suficiente en el ideal normativo de los Derechos Humanos, de tal forma que no quede expuesto al albur de unas meras contingencias históricas y jurídicas, por muy "consensuadas» que parezcan. Si las fundamentaciones neocontractualistas o neocomunitaristas siguen siendo insuficientes, habrá que articular nuevas fórmulas de fundamentación, que permitan trascender tanto el escepticismo como el dogmatismo.

Así, pues, apelar hoy al ideal normativo de los Derechos Humanos, no debe significar que creemos que existen mandatos «absolutamente absolutos» por «incondicionados», ya que la historicidad constitutiva del ser humano es característica, también, como hemos visto, de los derechos humanos que nacen para dar razón de su dignidad. Con todo, sí podemos afirmar que existen valores universales, que pueden defenderse con argumentos intersubjetivamente aceptables y que tienen su núcleo en el valor absoluto de las personas concretas. Sin embargo, hablar de "valores absolutos», o de "derechos fundamentales», no nos evita tener que asumir que las contradicciones generadas por su aplicación nos obligan a jerarquizarlos y priorizarlos (así, los de la primera generación serían prioritarios), lo que no significa que estamos abocados al relativismo.

Más allá del absolutismo y del relativismo, podemos seguir afirmando, avalados por la mejor tradición del pensamiento occidental, que las personas no deben ser objetivadas o instrumentalizadas en ningún caso, ya que son «sujetos» de derechos y gozan de una dignidad que siempre debe ser «reconocida». Allá donde no se reconozca el derecho a la vida, a la libertad y a la disponibilidad de los recursos mínimos para poder vivirlas dignamente, como afirman los derechos humanos de la primera y segunda generación, estaremos en sociedades que no alcanzan el umbral de lo que una razón intersubjetiva universal puede llamar «humana» ${ }^{6}$.

6 Sería interesante analizar críticamente, como lo he realizado en otros contextos, la fundamentación de la universalidad de los derechos humanos en jusnaturalistas modernos (como Finnis, Correa-Massini, Beuchot y otros), así como la posibilidad de afirmar la universalidad de los derechos humanos sin «un coto cerrado» de «intención jusnaturalista» (que no cae en la falacia naturalista ni en el formalismo dogmático del jusnaturalismo) como el constructivismo y la hermenéutica (Rawls, Habermas, Ricoeur, etc). El análisis de la obra del mismo Rawls (sobre todo, su tránsito de Teoría de la Justicia a «Derecho de Gentes»o Política Liberal) permite abundar en la discusión sobre la problemática planteada por el multiculturalismo y el relativismo ante la universalidad de los derechos humanos (Rawls, 1971, 1996 y 1997). 


\subsection{Algunas propuestas significativas}

Urge, pues, garantizar la protección y promoción de los derechos humanos, aplicando todas las declaraciones, los pactos, las convenciones y las cartas, que así lo han venido exigiendo desde hace más de dos siglos. Pero no urge menos seguir trabajando en la creación de un imaginario social tan realmente convincente y hegemónico que convierta todos esos textos jurídicos en el código de conducta que rija las relaciones entre los seres humanos que habitamos el planeta tierra.

A pesar de la dificultad de toda pretensión fundamentadora, hay algunas propuestas que son especialmente significativas, en primer lugar, porque han sido formuladas desde la asunción crítica de las fundamentaciones históricas de los derechos humanos, y, sobre todo, porque pretenden reflejar la experiencia crítica de las víctimas, que siguen gritando "no hay derecho» y lo hacen con vocación universalmente humanizadora. Me refiero a figuras como los ya citados Ferrajoli, Dussel o de Sousa.

Ya nos hemos referido a Dussel, quien plantea de una forma seria y coherente lo que significa fundamentar un proyecto liberador como el de los derechos humanos. La praxis liberadora de «los sin derechos» y la creación de los derechos humanos encuentran su legitimación racional en la construcción de una ética, a la vez formal y material, que partiendo del grito del sujeto concreto y viviente, la víctima en la situación actual del sistema-mundo, se convierte en el "clamor del pueblo que gime en la esclavitud de Egipto» y que, bajo la forma de nuevos movimientos sociales que luchan por el reconocimiento y la justicia social, se transforma en la nueva comunidad humana liberada y liberadora Dussel, 1998, 2001 y 2009).

De Sousa ofrece asimismo una nueva forma de entender y fundamentar los derechos humanos en clave emancipadora. Su cartografía jurídica y su hermenéutica diatópica le permiten esbozar una "concepción multicultural de los derechos humanos», en las que se supera tanto la falsa universalidad de los derechos humanos (a los que en su formulación convencional considera expresión de un «localismo globalizado»), como la fragmentación social provocada por el multiculturalismo identitario (De Sousa 2003a, 2003b, 2014 y Sena y De Sousa 2019).

Confrontando este pesado legado, que ha limitado en mucho las posibilidades de emancipación de dichos derechos humanos, procuramos mostrar cómo, a partir de las Epistemologías del Sur, las luchas por el derecho a ser humano (el derecho a la vida digna y a la memoria de las indignidades históricas ampliamente silenciadas) tienen 
que ser fundadoras de una concepción renovada contrahegemónica de los mismos. En un tiempo que carece desesperadamente de narrativas de transformación social, más que ver los derechos humanos como la gramática salvadora que sobrevivió en medio de las ruinas de utopías pretéritas, es importante que entendamos que el trabajo de traducción es hoy la única alternativa.

\section{Repensar los derechos humanos desde el mundo de los «sin derechos»}

Tras siglos de proclamar los DDHH hemos creado un mundo en el que han crecido de forma significativa el número de seres humanos "sin derechos». Un mundo en gran medida controlado por poderes no legitimados democráticamente, pero que imponen a individuos, grupos humanos e incluso a Estados sus propias reglas de juego. Un mundo en el que el Neoliberalismo se ha convertido en la ideología hegemónica que, a pesar de lo dicho, sigue afirmando que todos y cada uno de los seres humanos gozan de «autonomía» y son responsables de su forma de pensar y de vivir, exculpando así al sistema capitalista de su pecado estructural. Si los individuos no son capaces de sacar adelante su «empresa», como "autónomos», es porque son unos fracasados. Si, además, quieren denunciar a los demás de la injusticia y de la desigualdad que padecen es porque son unos resentidos irresponsables. Teniendo presente que las grandes Declaraciones de Derechos Humanos se realizaron en nombre de la autonomía individual, la pregunta obvia es si es ya posible rescatar de los derechos humanos su potencial emancipador cuando la razón cínica neoliberal ha pervertido y vaciado de contenido dicha autonomía.

Es plausible pensar que dicha autonomía venía ya pervertida desde sus orígenes liberales por el individualismo propietarista, responsable de las situaciones de injusticia y desigualdad que han negado las condiciones de posibilidad a toda autonomía humana razonable. Si es así, cabe preguntarse si el pretendido carácter performativo de las grandes Declaraciones de los Derechos Humanos no ha sido más que un espejismo propio del voluntarismo de sus voceros. Estas cuestiones cobran especial significación si tenemos presente la lacra que hoy determina de forma dramática el presente y el futuro de los derechos humanos. Me refiero a la desigualdad. No voy a extenderme aquí en abordar un tema tan fundamental y complejo como éste. Me remito a algunos textos que recientemente han abundado en explicaciones 
de gran solvencia científica y social7. Ahora quiero resaltar que la escandalosa y creciente desigualdad es, como ya decía la Sollicitudo Rei Socialis (1987), la gran brecha criminal que hiere literalmente de muerte a la humanidad ${ }^{8}$. Por eso, en mi opinión, las tesis de quienes defienden al capitalismo actual porque no tiene alternativa alguna y, además porque garantiza el poder vivir más y mejor que nunca, olvidan algo que autores como Stiglitz (2020) han venido reiterando: "evolucionamos de manera resuelta hacia una economía y una democracia del $1 \%$, por el $1 \%$ y para el $1 \% »$.

Vivimos una situación de fascismo social, como ha argumentado en numerosas ocasiones de Sousa, en la que este individualismo propietarista y depredador se ha convertido en una amenaza letal para la misma supervivencia de gran parte de la humanidad y también de la madre tierra que la posibilita. Este fascismo, aplicado al orden global, se ha impuesto contra la autonomía y el desarrollo de los pueblos, garantizando así la apropiación y el control de todo aquello que pueda considerarse valioso en el intercambio del mercado, aunque se trate de los bienes comunes necesarios para satisfacer las necesidades humanas básicas. Esta situación es radicalmente novedosa respecto a la percepción que los revolucionarios pudieron tener de su mundo. Los retos a los que nos enfrentamos hoy son de tal envergadura que posiblemente la única salida sea repensar un nuevo orden ontológico revolucionario y una nueva forma de entender la centralidad del sujeto humano individual y colectivamente contemplado. En este contexto, la pregunta pertinente es si es posible la traducción de la experiencia y narrativa revolucionaria, que posibilitó el salto de una sociedad como la del Antiguo Régimen a una nueva sociedad. Antes, me he referido a algunas propuestas significativas a este respecto, como las de Dussel o de Sousa. A continuación, recojo la de Ferrajoli. Este autor propone una nueva refundación de la política que sea alternativa a la irracional y profundamente injusta situación política actual (Ferrajoli 2019).

7 Ver Rousseau (1986), Stiglitz (2012), Rosanvallon (2012), Piketty (2013 y 2019), Ferrajoli (2019) y Velasco (2010 y 2015)

8 «Una de las mayores injusticias del mundo contemporáneo consiste precisamente en esto: en que son relativamente pocos los que poseen mucho, y muchos los que no poseen casi nada. Es la injusticia de la mala distribución de los bienes y servicios destinados originariamente a todos. Este es, pues, el cuadro: están aquellos - los pocos que poseen mucho-que no llegan verdaderamente a «ser», porque, por una inversión de la jerarquía de los valores, se encuentran impedidos por el culto del «tener»; y están los otros -los muchos que poseen poco o nada- los cuales no consiguen realizar su vocación humana fundamental al carecer de los bienes indispensables» (Sollicitudo Rei Socialis. n. 28). 


\subsection{Hacia un nuevo orden ontológico revolucionario, hoy}

Si lo que realmente está en juego es la vida humana, en el sentido literal, tanto para una gran parte de la humanidad como para el futuro del planeta tierra que la cobija, será necesario, como plantea Dussel, partir de «la voluntad de vivir» que, bien entendida, no debe confundirse nunca con la «voluntad de poder» nietzscheana, como:

el fundamento positivo último que nos permita describir la voluntad del poder político en su sentido fuerte, como pretensión de verdad y de legitimidad, desde donde sea posible criticar las descripciones defectivas, reductivas de dicho poder. El ser humano como ser viviente, es decir, como corporalidad concreta que es cada uno, es la realidad misma de la que se parte. Ha de tenerse en cuenta que esa corporalidad es una realidad constituida esencialmente por la falta de realidad. Su realidad es una realidad hambrienta, una sed inextinguible... Estamos entonces en plena ontología (Dussel 2009, 47-51).

Esta voluntad de vivir que es la base y el sentido del poder político legítimo está negada en la forma de ejercer el poder en la casi totalidad de la historia de la modernidad. "La Política de la Liberación parte y se funda en esa Voluntad de Vivir como el poder que pone las mediaciones para cumplir con el principio de justicia, de la paz, de la permanencia y aumento de la vida de la comunidad política» (Dussel 2009 , 59). Para Dussel no es posible salir de la situación de dominación irracional e injusta que rige nuestro mundo si no se recupera este concepto ontológico positivo del poder y desde él se construye toda la arquitectónica política. En la tercera parte del volumen, dedicada a los principios normativos fundamentales de la política, comenzando por el principio democrático de la igualdad, hay un texto que trata de la voluntad de vivir que "da lugar» al Otro, como una afirmación de alteridad y, a la vez, del reconocimiento mutuo, en el que comenta a Hönneth (1997), que recojo aquí porque me permitirá enlazar con el apartado de los «sin derechos»:

El amor entre los miembros en el nivel de la voluntad, el reconocimiento de ser una persona libre jurídicamente en el de la racionalidad discursiva, y el de una valoración social que les permite referirse positivamente a sus cualidades y facultades concretas en el nivel social, son el fundamento para el reconocimiento de la igualdad del otro. Estos tres momentos positivos se oponen a otros momentos negativos o de «menosprecio» que marcan la diferencia 
negativa: odio, maltrato y violación, desposesión de derechos y desconocimiento de la dignidad y honor del Otro, aspectos de la denigración como desigualdad (Dussel 2009, 398).

Hoy, dice de Sousa, la verdadera urgencia está en garantizar los derechos básicos a satisfacer las necesidades básicas fundamentales, algo previo a los derechos convencionales a la libertad, la igualdad, como es comer, beber, reproducirse en condiciones de mínima dignidad. El derecho a la tierra, al agua, al medio ambiente, exige estrategias nuevas de legitimación política y de plausibilidad histórica, ya que las actuales no garantizan el primer criterio de "verdad práctica» que es la reproducción de la vida, como afirma Dussel.

Ferrajoli (2019) ilustra los hechos más relevantes que confirman la necesidad de crear un nuevo orden ontológico revolucionario en el que se garanticen los derechos básicos de todos los seres humanos y en el que vuelva a tener sentido el ejercicio de una política razonable que reúna las condiciones ya señaladas por Dussel de "verdad práctica», de legitimidad política y de plausibilidad histórica y que inspiren al constitucionalismo del futuro. El primer hecho es el de los migrantes, ejemplo paradigmático de las personas «sin derechos»; el segundo es el de la amenaza al medio ambiente y a los bienes comunes necesarios para garantizar la vida humana sobre la tierra.

El fenómeno de la inmigración es posiblemente el que de forma más plástica y dramática refleja hasta dónde nuestra sensibilidad respecto a los derechos humanos puede anestesiarse e incluso pervertirse. Cada día podemos ver cómo millones de seres humanos se ven obligados a huir de situaciones de hambre, de guerra y de persecuciones de todo tipo. Tras arriesgarse a poner en juego sus vidas y a convertir sus rutas de huida en improvisados cementerios, llegan a unos supuestos países civilizados en los que se ven sometidos a condiciones de inhumanidad difícilmente imaginables. Como son considerados intrusos indeseados, se les reduce a vivir como "personas ilegales», carentes de derechos y, por tanto, condenados a vivir en la clandestinidad y a convertirse en objetos de explotación y de discriminación crueles. Cuando escribo estas líneas, nos llegan una vez más las imágenes de la dramática situación de multitudes de inmigrantes y refugiados, que malviven en tierra de nadie o en campos de concentración, y a los que la Europa de los derechos y de las libertades cierra sus fronteras. Seguiremos hablando de graves crisis humanitarias, pero instalados en el indolente y cínico «mañana le abriremos respondía, para lo mismo responder mañana». 
En efecto, suena a cínico invocar hoy el derecho humano del ius migrandi, del que Ferrajoli $(2019,190)$ dice que es el

más antiguo derecho teorizado como natural, proclamado en los orígenes de la civilidad jurídica occidental. [...] Después de cinco siglos de colonizaciones y rapiñas, de tratas de esclavos y masacres, ya no son los occidentales los que tienen que emigrar a los países pobres del mundo, a conquistarlos y depredarlos, sino que, por el contrario, son las masas de hambrientos de estos países las que llaman a nuestras fronteras. Y con la inversión de la asimetría se ha producido también un vuelco del derecho. Hoy, cuando el ejercicio del derecho de emigrar se ha hecho materialmente posible para todos y es, además, la única alternativa de vida para millones de seres humanos, no solo se han olvidado su origen histórico y su fundamento jurídico en la tradición occidental, sino que se lo reprime con la misma feroz dureza con la que se lo blandió en los orígenes de la civilidad moderna con fines de conquista y colonización.

Ferrajoli denuncia con sólidos argumentos el racismo institucional que alimenta un círculo vicioso, en el que, tras privar de derechos al inmigrado y percibirlo como antropológicamente desigual, se legitima que sea discriminado y penalizado; el sadismo legislativo y la criminalización del estatus de inmigrado clandestino que pervierte gravemente el alcance y sentido del derecho penal ya que se castiga no por lo que se hace, sino por lo que se es, y se extreman las medidas injustificadas para seguir excluyendo al inmigrante; el sadismo burocrático y un derecho administrativo antihumanitario, que, basándose en la creación de un estereotipo de inmigrado-delincuente, construido por la demagogia seguritaria, se condenan a categorías enteras de personas por razones étnicas e identitarias. Este racismo institucional sirve para agravar todos los problemas que relacionados con la inmigración se dice querer resolver. No cabe duda de que esta praxis es propia de una Europa que ha renunciado a mantener su pretendida identidad de Europa de los derechos y ha tomado la peligrosa deriva de los particularismos excluyentes.

Es obvio que en la secular dicotomía entre los derechos de ciudadanía y derechos del hombre se ha afirmado de forma escandalosa una ciudadanía hipotecada por las lógicas antidemocráticas: la nacionalitaria, la burguesa, la patriarcalista y la jurídico administrativa, olvidándose de su otra lógica revolucionaria: la democrática, igualitaria y universalizadora. La ciudadanía ha funcionado, como ya dijera Brubaker, como un instrumento de cierre y de exclusión social que ha permitido llegar a las aberraciones de las que acabamos de hablar (Velasco 1997, 2002 y 2013b). 
Ante esta situación, parece razonable pensar en la construcción de un nuevo orden ontológico que priorice los derechos del hombre sobre los del ciudadano. Esto solo es posible si, como ocurrió, con las revoluciones liberales, somos capaces de hacer verosímil lo utópico. La experiencia nos ha enseñado que los derechos no han llovido del cielo, sino que los excluidos y las víctimas en una situación de extrema inhumanidad han sido capaces de gritar el "no hay derecho» y dar un vuelco revolucionario a dicha situación. La presión del fenómeno migratorio, en un mundo cada vez más globalizado y amenazado por la anomía y el egoísmo autodestructor, nos obliga a una razonable apuesta por una refundación de la política, del derecho y de la democracia. Me parece sugerente lo que dice Ferrajoli $(2019,2005)$ respecto al:

pueblo de los migrantes como "sujeto constituyente» de un nuevo orden mundial y, al mismo tiempo, de la humanidad como sujeto jurídico. Por tres razones: la primera ligada a las espantosas desigualdades materiales que provocan las migraciones; la segunda ligada a tantas diferencias de identidad como atraviesan el pueblo de los migrantes; la tercera ligada a las desigualdades de los derechos y a las diferencias de estatus que dividen siempre a la humanidad ${ }^{9}$.

Respecto al segundo de los hechos señalado por Ferrajoli, el de "la amenaza al medio ambiente y a los bienes comunes necesarios» para garantizar la vida humana sobre la tierra, creo que hay suficientes evidencias para concluir que estamos ante otra situación aberrante e insostenible. De nuevo, la lógica del individualismo posesivo de un capitalismo cada vez más anómico y desbocado ha llegado a convertir los bienes comunes y básicos, que siempre se habían considerado de uso universal y destinados a satisfacer las necesidades vitales de todos los seres humanos, en bienes comercializables y apropiables por quien tenga poder y recursos para ello. Nos referimos a bienes tan básicos como los que la naturaleza nos ofrece: aire, agua, mares, equilibrio climático, etc. Cuando la lógica propietarista ha considerado que estos bienes comunes pueden ser escasos, los ha convertido en bienes privatizables y ha sacado a relucir su carácter radicalmente depredatorio: primero, por un desarrollismo de efectos devastadores y destructivos hasta convertirse en una amenaza grave para el ecosistema planetario; segundo, convirtiendo en bienes patrimoniales

9 Recuerda a la posición de Habermas respecto a la construcción de una ciudadanía postnacional y cosmopolita, más concretada en la ciudadanía europea... 
los que, siendo cada vez más escasos, siguen siendo vitales para la supervivencia de la humanidad y para la sostenibilidad del planeta. Es casi apocalíptica la descripción de los daños irreversibles que de forma exponencialmente graves están produciendo a los bienes comunes. Si a esto añadimos la producción de ingentes bienes mortíferos artificiales, como son las armas de destrucción masiva y el riesgo de su uso bélico y criminal, el panorama es desolador. Es verdad que la capacidad tecnológica es capaz de producir también bienes vitales artificiales, como los dedicados la salud, la alimentación y a la mejora de la calidad de la vida. Lástima que incluso estos logros tan prometedores sean asimismo objetos del apetito depredador de que hemos hablado.

Creo que Hobbes, desde sus reflexiones más sombrías sobre el mundo amenazador que provoca en el individuo el "fame futura famelicus» (hambriento del hambre que puede tener mañana), nunca pudo imaginar la deriva de una situación como la que estamos describiendo. Su Leviatán la habría atajado de raíz. Ojalá, hoy, sepamos plantearnos la necesidad de un nuevo orden constitucional que garantice como derechos fundamentales «los bienes fundamentales», impidiendo que se conviertan en bienes patrimoniales, o, al menos, que cuando los bienes patrimoniales sean legítimos estén siempre subordinados al ejercicio de los derechos fundamentales de los demás seres humanos. Los «bienes fundamentales», como dice Ferrajoli, incluyen los bienes comunes (naturales como el agua el aire y el medio ambiente y artificiales como internet), los bienes personalísimos (indisponibilidad del cuerpo humano y libertad frente a lesiones) y los bienes sociales (los derechos sociales básicos como la salud y los alimentos básicos).

En suma, se impone con urgencia una fase nueva del constitucionalismo, a la altura de nueva fase del capitalismo y de los progresos tecnológicos. Reconocer y garantizar determinados bienes vitales como fundamentales quiere decir configurarlos como bienes constitucionales a fin de sustraerlos a la disponibilidad tanto de la política como del mercado, para, de este modo, asegurar el goce igualmente a todos. Más precisamente, quiere decir estipularlos en normas constitucionales dotadas de rigidez absoluta. Por tanto, la garantía de tales bienes comunes consiste en la obligación de su prestación gratuita cuando se trate de bienes sociales, y en la prohibición de su lesión o comercialización cuando se trate de bienes personalísimos o de bienes comunes (Ferrajoli 2019, 222).

Esta propuesta de Ferrajoli puede parecer fruto del voluntarismo, dada la situación de nuestro mundo, que parece avanzar de espaldas 
al constitucionalismo en todos los ámbitos de la vida social y política (local, nacional, global). Sin embargo, coincido con él en que hay una razón para el optimismo que paradójicamente se basa en que la amenaza de la destrucción puede alanzarnos a todos. El miedo puede convertirse una vez más en un aliado para lograr el consenso en los mínimos que garanticen la supervivencia de la humanidad y del planeta. Quizá deberíamos releer a Hans Jonas y aprender que el miedo puede servirnos para, desde "el principio de responsabilidad», hacernos cargo del mundo que hemos creado. Al fin y al cabo, como ya hemos dicho, fabula de nobis narratur.

También me parece pertinente leer algunos textos escritos por al actual papa Francisco que pueden contagiarnos de una buena dosis de esperanza. Esto sirve especialmente a los que nos llamamos cristianos, pero que creo que vale igualmente para quienes, sin ser creyentes, quieren leer unos textos magníficos que nos permiten tomar conciencia de la envergadura de los retos y de la urgencia de soluciones razonables a los mismos. Me refiero, en primer lugar, a la encíclica Laudato SI'. Sobre el cuidado de la casa común (24N/2015) y a la reciente exhortación apostólica postsinodal Querida Amazonía (2/II/2020). Ambos textos aportan un análisis lleno de lucidez sobre la crisis ecológica y sus raíces antropológicas, así como una respuesta a la misma orientada a la práctica de una ecología integral, alimentada por una teología de la creación y por una educación y una espiritualidad ecológicas. La Amazonía es el epicentro de una experiencia novedosa en este sentido que merece ser conocida. En segundo lugar, la Encíclica Evangelii Gaudium (2013) que sale al paso de los retos más importantes de nuestros días, descritos con gran realismo, y ofrece la «eterna novedad» del evangelio cristiano y la llamada al compromiso social que de éste se desprende. La causa de los derechos humanos está intrínsecamente vinculada con la construcción de una comunidad de seres humanos libres e iguales en la fraternidad.

\section{Referencias bibliográficas}

Cabo, Antonio de y Pisarello, Gerardo, eds. 2005. Los fundamentos de los Derechos Fundamentales. Madrid: Trotta.

De Sousa, Boaventura. 2003a. "Hacia una concepción multicultural de los derechos humanos». En La protección Internacional de los Derechos humanos en los albores del siglo XXI, editado por Felipe Gómez Isa, 95122. Bilbao: Humanitarian Net y Universidad de Deusto.

De Sousa, Boaventura. 2003b. Crítica de la Razón Indolente. Contra el desperdicio de la experiencia. Bilbao: Desclée de Brouwer. 
De Sousa, Boaventura. 2009. Sociología jurídica crítica. Para un nuevo sentido común en el derecho. Madrid: Trotta.

De Sousa, Boaventura. 2014. Derechos humanos, democracia y desarrollo. Bogotá: Centro de Estudios de Derecho, Justicia y Sociedad, Dejusticia.

Dussel, Enrique. 1998. Ética de la liberación. Madrid: Trotta.

Dussel, Enrique. 2001. Hacia una filosofía política crítica, Bilbao: Desclée de Brouwer.

Dussel, Enrique. 2009. Política de la Liberación. Volumen II: Arquitectónica, Madrid: Trota.

Ferrajoli, Luigi. 2019. Manifiesto por la igualdad. Madrid: Trotta.

Ferrajoli, Luigi. 2013. Los fundamentos de los derechos fundamentales. Madrid: Trotta.

Hönneth, Axel. 1997. Lucha por el reconocimiento, Barcelona: Crítica.

Pérez-Luño, Antonio E. 1994. «Derecho, Moral y Política: tensiones centrípetas y centrífugas», Doxa, n. 15-16: 511-534.

Piketty, Thomas. 2013. El Capital en el siglo XXI. México: Fondo de Cultura Económica.

Piketty, Thomas. 2019. Capital e Ideología. Bilbao: Ed. Deusto

Rawls, John. 1971. Teoría de la Justicia. México: Fondo de Cultura Económica.

Rawls, John. 1996. El liberalismo político, Barcelona: Crítica.

Rawls, John. 1997. «El derecho de gentes», Isegoría 16: 5-36.

Rosanvallon, Pierre. 2012. La sociedad de los iguales. Barcelona: RBA

Rousseau, Jean-Jacques. 1986. Discurso sobre el origen y los fundamentos de la desigualdad entre los hombres. Madrid: Alianza.

Sena, Bruno y De Sousa, Boaventura. 2019. El pluriverso de los derechos humanos. Madrid: Akal.

Stiglitz, Joseph. 2012. El precio de la desigualdad, Madrid: Taurus

Stiglitz, Joseph. 2020. Capitalismo progresista, Madrid: Taurus

Taylor, Charles. 2006. Imaginarios Sociales. Barcelona: Paidós

Velasco, Demetrio. 1997. "Raíces histórico-ideológicas del extranjero», en El extranjero en la cultura europea de nuestros días. 345-384. Bilbao: Universidad de Deusto.

Velasco, Demetrio. 1999. «Antecedentes histórico-ideológicos de la DUDH de 1948». En La Declaración Universal de los Derechos Humanos en su cincuenta aniversario. Un estudio interdisciplinar, editado por Felipe Gómez Isa, 203-308. Bilbao: Universidad de Deusto.

Velasco, Demetrio. 2002. Ética y políticas para una ciudadanía universal, Bilbao: IDTP/Desclée de Brouwer.

Velasco, Demetrio. 2004. «Errores y silencios de la Doctrina Social de la Iglesia», Iglesia Viva, n. 219: 103-116.

Velasco, Demetrio. 2005. "Tocqueville (1805-1859) dos siglos después», Estudios de Deusto 53, n. 1: 183-250.

Velasco, Demetrio. 2006. «Repensar laicamente la democracia y la praxis cristiana», Estudios de Deusto 54, n. 1: 219-281.

Velasco, Demetrio. 2010. "La quiebra de lo humano en la difícil lucha contra la desigualdad», Iglesia Viva n. 244: 61-82. 
Velasco, Demetrio. 2013a. Fascismo social: políticas del miedo y servidumbre voluntaria. ¿Qué hacer? Bilbao: Universidad de Deusto.

Velasco, Demetrio. 2013b. "Ciudadanía republicana y exclusión, hoy», en Libro homenaje a J. García Roca. Madrid: HOAC

Velasco, Demetrio. 2015. "La actitud de los cristianos/as ante la desigualdad», Éxodo n. 131: 29-41. 


\section{Copyright}

Deusto Journal of Human Rights / Revista Deusto de Derechos Humanos is an Open Access journal; which means that it is free for full and immediate access, reading, search, download, distribution, and reuse in any medium only for non-commercial purposes and in accordance with any applicable copyright legislation, without prior permission from the copyright holder (University of Deusto) or the author; provided the original work and publication source are properly cited (Issue number, year, pages and DOI if applicable) and any changes to the original are clearly indicated. Any other use of its content in any medium or format, now known or developed in the future, requires prior written permission of the copyright holder.

\section{Derechos de autoría}

Deusto Journal of Human Rights / Revista Deusto de Derechos Humanos es una revista de Acceso Abierto; lo que significa que es de libre acceso en su integridad inmediatamente después de la publicación de cada número. Se permite su lectura, la búsqueda, descarga, distribución y reutilización en cualquier tipo de soporte sólo para fines no comerciales y según lo previsto por la ley; sin la previa autorización de la Editorial (Universidad de Deusto) o la persona autora, siempre que la obra original sea debidamente citada (número, año, páginas y DOI si procede) y cualquier cambio en el original esté claramente indicado. Cualquier otro uso de su contenido en cualquier medio o formato, ahora conocido o desarrollado en el futuro, requiere el permiso previo por escrito de la persona titular de los derechos de autoría. 